N. Zuntz: Ueber die Unwirksamkeit des Curare vom Magen her. 437

\title{
Ueber die Unwirksamkeit des Curare vom Magen her.
}

Vorläufige Notiz über die Versuchsergebnisse des Herrnstud. med. vet. Jess.

Von

\section{N. Zuntz.}

Eine Schutzwirkung der Leber gegenüber dem rom Magen résorbirten Curare ist durch die vorstehenden Versuche des Herrn Sauer ausgeschlossen. - Es fragte sich nun, ob es überhanpt resorbirt wird? Herr Jess untersuchte zu diesem Behufe die Giftwirkung des Kaninchenharns nach Curarevergiftung an Fröschen. Der in den nächsten 24 Stunden nach Einfuihrung von $250 \mathrm{mgr}$ Curare in den Magen gebildete Urin war bedentend weniger wirksam als der in 4 Stunden nach subcutaner Einfuhhrung von $30 \mathrm{mgr}$ secernirte. Das Kothextract der mit Curare gefütterten Thiere zeigte keinerlei Giftwirkung.

In Analogie zu der Beobachtung Boehm's ${ }^{1}$, dass sich $\mathrm{Cu}$ rare beim Eindampfen in saurer Lösung rasch zersetzt, zeigte sich bei längerem Digeriren mit Magensaft eine fortschreitende Abschwächung der Giftigkeit einer Curarelösung. -- Herr Jess ist noch mit genaueren quantitativen Bestimmungen beschäftigt und wird s. Z. darïber berichten.

1) Boehm in der Festschrift für C. Ludwig 1887, S. 187. 